\title{
Barriers and challenges against the utilization of novel teaching methods for nursing students from the perspective of nursing instructors
}

Mostafa bijani ( $\sim$ bizhani_mostafa@yahoo.com )

Fasa University of Medical Science

\section{Zahra Moradi}

Fasa University of Medical Science

Shahnaz Karimi

fasa university medical scinces

\section{Zhila Fereidouni}

Fasa University of Medical Science

\section{Leila Nikrooz}

Fasa University of Medical Science

\section{Mahmood Hatami}

Fasa University of Medical Science

\section{Mohammad Mehdi Naghizadeh}

Fasa University of Medical Science

\section{Research article}

Keywords: Nursing, Education, Student

Posted Date: March 30th, 2020

DOl: https://doi.org/10.21203/rs.3.rs-19853/v1

License: (9) This work is licensed under a Creative Commons Attribution 4.0 International License. Read Full License 


\section{Abstract}

Background: The first step in efficient application of novel teaching methods is identification of barriers and challenges in order to perform appropriate interventions. Various studies have emphasized the utilization of novel methods in instruction of nursing students. However, there are barriers and challenges against the use of these techniques. Therefore, the present study aimed to investigate the challenges and executive barriers against the utilization of novel approaches in instructing nursing students from the perspective of nursing instructors.

Methods: In this descriptive-analytical study, 150 nursing instructors were selected through census from three nursing schools in Fars province, southwest of Iran in 2019. The study data were entered into the SPSS 22 software and were analyzed using statistical tests, frequency distribution, mean, standard deviation, t-test, and one-way ANOVA.

Results: The effective challenges against the utilization of novel teaching methods were classified into three domains as follows: challenges related to students, challenges related to instructors, and structuralmanagerial challenges. Considering the challenges associated with students, the highest score was related to the students' lack of familiarity with novel teaching methods. Regarding the challenges associated with instructors, the highest scores were related to the instructors' unfamiliarity with novel teaching methods and lack of mastery and skills. Finally, the large number of students and lack of support and encouragement on the part of educational institutions obtained the highest scores in the field of structural-managerial challenges. The results of independent t-test revealed a significant relationship between gender and educational degree in all three domains $(p<0.001)$. The results also showed a significant relationship between work experience and the scores of the three domains $(p<0.001)$.

Conclusion: Application of novel approaches in nursing education requires infrastructures as well as elimination of executive barriers. Instructors' and students' familiarity with novel techniques and their execution processes and educational institutions' support could contribute to the effectiveness of these methods, as well.

\section{Background}

Education is a complicated process, particularly in medical sciences where graduates are faced with clients requiring complex services [1]. Education in medical sciences should aim at training skillful, ethical, research-oriented, entrepreneur, and reflexive students who are ready to encounter challenging and complicated work environments. Training such students is quite a difficult task and requires great infrastructures [2]. One of the strategies for promotion of the quality of medical students' education is changing teaching techniques [3]. A successful instructor is the one who makes the learning process more effective via following teaching principles and coordinating teaching methods with the students' learning styles [4]. In fact, an instructor's teaching method is the main source of adjustment of interaction 
styles in the classroom as well as an important factor in motivating students and enhancing their cooperation [5]. In this context, awareness of teaching methods, conformity of these methods to the students' learning styles, and variety in utilization of these techniques have considerable effects on the learners' learning and satisfaction. Dynamic teaching and learning styles also support the learners' satisfaction. In spite of the variety of teaching methods applied in medical sciences nowadays, a large number of instructors still make use of the lecture method $[6,7]$.

Considering the positive effects of novel teaching methods based on problem-solving, role of selforientation in learning, and impact of lifelong learning on medical students, it is necessary to develop and implement student-centered methods based on learning theories in universities and provide opportunities for improvement of learning among nursing students as healthcare providers [8]. In fact, traditional teaching methods cannot respond to the needs of the educational system anymore. Today, instructors seek for methods that lead to active learning among students and strengthen their critical thinking and decision-making skills [9].

Although numerous studies have emphasized the utilization of novel approaches in nursing students' education $[10,11]$, Traditional methods such as lecturing are still the top priority of many faculty members in Iran [12]. Ghojazadeh, et al. (2015) stated that novel teaching methods cannot be accurately and standardly executed in Iran unless they are accompanied with time, place, and personnel arrangements [13].

The present study aims to assess the instructors' perspectives regarding the reasons for not making use of novel teaching methods as well as the challenges against selecting and utilizing these techniques. Review of the literature revealed no studies on nursing instructors' viewpoints regarding the reasons for not using novel teaching methods. Therefore, the researchers decided to determine the challenges against and strategies for making use of novel teaching methods among nursing faculty members through brain storming, so that by analyzing the results, steps could be taken towards planning for employing novel teaching techniques in nursing education.

\section{Methods}

This descriptive-analytical study aimed to explore the challenges and executive barriers against the utilization of novel teaching approaches from the perspective of nursing instructors in 2019. The participants included 150 faculty members selected through census from three nursing schools in Fars province, southwestern Iran. It should be noted that there were 161 faculty members in these three nursing schools. However, 11 instructors were excluded due to maternity leave $(n=3)$, continuing education $(n=5)$, and incomplete questionnaires $(n=3)$. Therefore, 150 questionnaires were completed. The inclusion criteria of the study were having at least one year of work experience and being willing to participate in the research. The exclusion criteria were incomplete questionnaires and lack of physical or mental preparedness. 
The study was carried out in two stages. The first stage involved designing a questionnaire for determining the challenges and strategies for eliminating the barriers against the utilization of novel teaching methods in nursing education from the perspective of nursing instructors. The questionnaire items were designed through literature review and nominal group technique. In doing so, 30 nursing instructors were invited to take part in the nominal group technique session in order to identify the challenges and barriers against the employment of novel teaching techniques. The nominal group technique session lasted for six hours and the nursing instructors' ideas about the reasons for not using novel teaching methods and the associated executive barriers were collected. These ideas were classified into three categories based on their similarities: challenges related to instructors, challenges related to students, and structural-managerial challenges. In other words, the phrases that pointed to a similar concept were put in one category. In this way, a questionnaire was developed and sent to the participants to determine the importance and scores of the items. Using group agreement and deep investigation of the participants' ideas, the challenges against the utilization of novel teaching techniques were thoroughly explored from the viewpoints of experts and stakeholders, so that strategies could be achieved for effective application of these techniques through collective wisdom. After all, the designed questionnaire contained 17 items categorized into three domains as follows: challenges related to students $(n=4)$, challenges related to instructors $(n=8)$, and structural-managerial challenges $(n=5)$. The items were scored via a five-point Likert scale ranging from five (

Very important) to one (Not important at all).

In order to assess the validity of the questionnaire, face and content validity were used. Quantitative face validity of the questionnaire was explored via impact score. In this regard, impact scores $>1.5$ represented the appropriateness of the items [14]. According to 20 nursing instructors, the impact scores of all questionnaire items were higher than 1.5. In order to investigate content validity, Content Validity Ratio (CVR) and Content Validity Index (CVI) were used. Considering CVR, the necessity of the items was determined by the experts as 'necessary', 'useful but not necessary', and 'not necessary' [15]. In doing so, use was made of 15 nursing instructors' opinions and values greater than 0.49 were considered to be acceptable based on Lawshe table [16]. Regarding CVI, the experts were requested to evaluate the items in terms of relevance, clarity, and simplicity. In this respect, scores above 0.79 were considered to be acceptable [17]. For this purpose, use was made of 15 nursing instructors' opinions. Accordingly, all items received scores above 0.79 . Moreover, the total content validity of the questionnaire was computed using $\mathrm{S}-\mathrm{CVI} /$ Ave where the minimum score of 0.79 was considered to be acceptable [18]. Based on the results, the S-CVI/Ave of the questionnaire was found to be 0.96 . Finally, the reliability of the questionnaire was assessed using the test-retest method. In doing so, the questionnaire was given to 100 nursing instructors in two stages with a two-week interval. The reliability coefficient of the questionnaire was found to be 0.89 .

The study data were entered into the SPSS 22 software and were analyzed using statistical tests, frequency distribution, mean, Standard Deviation (SD), t-test, and one-way ANOVA. 


\section{Results}

Out of the 150 nursing instructors under investigation, 96 (64\%) were female and 54 (36\%) were male. Additionally, 60 participants (40\%) had PhD degrees and 90 ones (60\%) had M.Sc. degrees. The mean age of the participants was $39 \pm 1.65$ years and their mean of work experience was $8 \pm 4.83$ years.

The mean scores of the challenges related to instructors, challenges related to students, and structuralmanagerial challenges were $33.24 \pm 7.16,16.31 \pm 3.93$, and $22.14 \pm 3.64$, respectively. Regarding the challenges associated with students, the highest score was related to the students' lack of familiarity with novel teaching methods. Considering the challenges associated with instructors, the highest scores were related to the instructors' unfamiliarity with novel teaching methods and lack of mastery and skills. Finally, the large number of students and lack of support and encouragement on the part of educational institutions obtained the highest scores in the field of structural-managerial challenges (Table 1). The results of independent t-test revealed a significant relationship between the instructors' gender and educational degree in all three domains $(p<0.001)$. The results also indicated a significant relationship between work experience and the scores of the three domains $(p<0.001)($ Tables $2-4)$.

\section{Discussion}

Utilization of novel teaching methods in nursing education could lead to active and deep learning and, consequently, long-term maintenance of the learned materials in the learners' minds [19]. However, there are some barriers and challenges against the utilization of these methods, which may cause them not to be welcomed in educational institutions. The present study aimed to investigate the executive barriers against the institutionalization of novel approaches in nursing education from the perspective of nursing instructors. Based on the results, the highest scores were related to the challenges associated with instructors and structural-managerial challenges, while the lowest scores were related to those associated with students. Considering the challenges associated with instructors and students, the highest score was related to their unfamiliarity with the novel teaching methods. Indeed, the large number of students and time restrictions obtained the highest scores in the field of structural-managerial challenges. Torabizadeh et al. (2018) explored the effective barriers against the utilization of novel approaches in clinical evaluation of nursing students in clinical environments based on the nursing instructors' viewpoints. The results revealed that the most important challenges included the nursing instructors' unfamiliarity with novel clinical evaluation techniques, large number of students, and lack of sufficient time, which was in agreement with the findings of the present investigation [20]. In the same line, Paula et al. (2012) and Hoseini et al. (2013) reported that large number of students, lack of facilities, and lack of awareness were challenges against the use of novel methods in education and clinical evaluation of nursing students [21, 22].. In the research performed by Wentink et al (2019) also, the instructors' lack of skills and unfamiliarity with novel teaching methods were introduced as effective factors. Hence, the instructors were recommended to gain the necessary trainings and skills in this field [23]. Moreover, Scicluna (2012) stated that the learners' professional capabilities have to be emphasized in medical education. Such education must aim at improvement of critical thinking skills, including clinical 
judgement, clinical reasoning, and clinical decision-making, which can be achieved via employment of novel educational approaches. Thus, instructors are recommended to get familiar with different types of novel educational approaches and gain the necessary awareness and preparedness in this regard [24]. Rafiee (2014) and Jamshidi (2016) also reported that the instructors' lack of sufficient knowledge and educational institutions' lack of support were effective barriers against the utilization of novel teaching approaches [25, 26].

\section{Limitation}

In the present study, only the nursing instructors' perspective investigated and the nursing students' perspective were not investigated. Therefore, it is suggested that future studies perspective of both groups be investigated and that this study be conducted in other countries as well.

\section{Conclusion}

The study findings indicated that application of novel approaches in nursing education required infrastructures as well as elimination of executive barriers. Instructors' and students' familiarity with novel teaching methods and their executive processes and educational institutions' managers' support and encouragement for executing these methods could help promote the utilization of these techniques and improve the quality of education.

\section{Declarations}

\section{Ethics approval and consent to participate}

This article was supported by the Vice Chancellor for Research, Fasa, University of Medical Sciences, Fasa, Iran (ethical code: IR.FUMS.REC.1398.124). Informed consent was obtained in writing through voluntary completion of the survey by respondents.

\section{Consent to publish}

Not applicable.

\section{Availability of data and materials}

The datasets used and /or analysed during the current study are available from the corresponding author on reasonable request.vailability of data and materials

\section{Competing interests}

The authors declare that they have no competing interests.

\section{Funding}


This research did not receive any specific grant from funding agencies in the public, commercial, or not for profit sectors.

\section{Authors' Contributions}

All authors ( $Z M, M B, S K, Z F, M H$ and $M M N$ ) have participated in the conception and design of the study. ZM and MB contributed the data collection and pre-pared the first draft of the manuscript. SK, Z F and $\mathrm{MH}$ critically revised and checked closely the proposal, the analysis and interpretation of the data and design the article. $\mathrm{ZM}, \mathrm{MB}$ and $\mathrm{MMN}$ carried out the analysis, interpretation of the data and drafting the manuscript. ZM, MB and SK have been involved in revising the manuscript critically. All authors read and approved the final manuscript.

\section{Acknowledgements}

This paper was extracted from a research project with the ethical code (IR.FUMS.REC.1398.124) in Fasa University of Medical Sciences, Fasa, Iran. The authors appreciate Fasa University of Medical Sciences for financially supporting this research.

\section{Authors' Information}

${ }^{1}$ School of Nursing, Fasa University of Medical Sciences, Fasa, Iran. ${ }^{2}$ Assistant Professor, School of Nursing, Fasa University of Medical Sciences, Fasa, Iran. ${ }^{3}$ Assistant Professor, School of Nursing, Fasa University of Medical Sciences Fasa, Iran. ${ }^{4}$ Assistant Professor, School of Nursing, Fasa University of Medical Sciences Fasa, Iran. ${ }^{5}$ Assistant Professor, School of Nursing, Fasa University of Medical Sciences Fasa, Iran. ${ }^{6}$ Master of Nursing, School of Nursing, Fasa University of Medical Sciences, Fasa, Iran. ${ }^{7}$ Noncommunicable Diseases Research, Fasa University of Medical Sciences, Fasa, Iran.

\section{References}

1. Buja, L.M. Medical education today: all that glitters is not gold. BMC Med Educ.2019; 19 (110):211 doi:10.1186/s12909-019-1535-9

2. Gutierrez CM, Cox SM, Dalrymple JL. The Revolution in Medical Education. Tex Med. 2016; 112(2):58-61. PMID: 26859376

3. Samarakoon L, Fernando T, Rodrigo C, Rajapakse S. Learning styles and approaches to learning among medical undergraduates and postgraduates. BMC Med Educ. 2013;13(42):26 https://doi.org/10.1186/1472-6920-13-42

4. Ahmed $\mathrm{MH}$. Are good attributes of medical teachers more important than the learning style: a glimpse into the future of medical education and learning. Journal of Public Health and Emergency. 2018;2(18):2-6 doi: 10.21037/jphe.2018.05.01

5. González, A., Conde, Á. Díaz, P., García, M., Ricoy, C. Instructors' teaching styles: relation with competences, self-efficacy, and commitment in pre-service teachers. Higher Education. 2017;75 (4): 
625-642 https://doi.org/10.1007/s10734-017-0160-y

6. Yazici HJ. Role of learning style preferences and interactive response systems on student learning outcomes. Int J Inf Oper Manag Educ. 2016;6(2):109-34.

7. Wang, R., Liu, C. The relation of dental students' learning styles to their satisfaction with traditional and inverted classroom models. BMC Med Educ. 2019;19 (315):2-8 https://doi.org/10.1186/s12909019-1749-x

8. Alghasham AA. Effect of students' learning styles on classroom performance in problem-based learning. Med Teach. 2012;34( 1): 14-19 doi: 10.3109/0142159X.2012.656744.

9. Bisrat H, Abel B, Salome W, Michael M, Sade H. Development of a New Innovative Teaching Method Using a Comprehensive Approach: A Survey of Students' Opinion. Biomed J Sci \&Tech Res. 2018;3(4):3494-3499 DOI: 10.26717/BJSTR.2018.03.000943

10. Horntvedt, M.T., Nordsteien, A., Fermann, T. et al. Strategies for teaching evidence-based practice in nursing education: a thematic literature review. BMC Med Educ.2018; 18( 172): 2-11 doi:10.1186/s12909-018-1278-z

11. McCurry MK, Martins DC.Teaching undergraduate nursing research: a comparison of traditional and innovative approaches for success with millennial learners. J Nurs Educ. 2010 May;49(5):276-9. doi: 10.3928/01484834-20091217-02.

12. Nouri JM, Ebadi A, Alhani F, Rejeh N. Experiences of role model instructors and nursing students about facilitator factors of role-modeling process: A qualitative research. Iran J Nurs Midwifery Res. 2014 May;19(3):248-54. PMID: 24949062

13. Ghojazadeh M, Azami-Aghdash S, Pournaghi Azar F. et al. A systematic review on barriers, facilities, knowledge and attitude toward evidence-based medicine in Iran. J Anal Res Clin Med. 2015; 3(1): 1-11. doi: 10.5681/jarcm.2015.001, http://journals.tbzmed.ac.ir/JARCM

14. Roberta H, Alison T. Validity and reliability in quantitative studies. Evid Based Nurs. 2015;18(3):66-70. doi: 10.1136/eb-2015-102129

15. Goldin IM, Pinkus RL, Ashley K. Validity and reliability of an instrument for assessing case analyses in bioengineering ethics education. Sci Eng Ethics. 2015 Jun;21(3):789-807. doi: 10.1007/s11948015-9644-2

16. Ayre A, Scally AJ. Critical Values for Lawshe's Content Validity Ratio: Revisiting the Original Methods of Calculation. Measurement and Evaluation in Counseling and Development. 2014; 47(1): $79-86$ https://doi.org/10.1177/0748175613513808

17. Kovacic D. Using the Content Validity Index to Determine Content Validity of an Instrument Assessing Health Care Providers' General Knowledge of Human Trafficking, Journal of Human Trafficking. 2018; 4(4): 327-335, DOI: 10.1080/23322705.2017.1364905

18. Connell, J., Carlton, J., Grundy, A. et al. The importance of content and face validity in instrument development: lessons learnt from service users when developing the Recovering Quality of Life measure (ReQoL). Qual Life Res. 2018;27:1893-1902 doi:10.1007/s11136-018-1847-y 
19. Shirani Bidabadi N, Nasr Isfahani AR, Rouhollahi A, Khalili R. Effective teaching methods in higher education: requirements and barriers. J Adv Med Educ Prof. 2016;4(4):170 -178. PMID: 27795967

20. Torabizadeh C, Ghodsbin F, Javanmardifard S, Shirazi F, Amirkhani M, Bijani M. The barriers and challenges of applying new strategies in the clinical evaluation of nursing students from the viewpoints of clinical teachers. Iranian J Nursing Midwifery Res. 2018;23(4):305-10 doi: 10.4103/ijnmr.IJNMR_17_17

21. 21. Palese A, Bulfone $G$, Venturato $E$. et al. The cost of the objective structured clinical examination on an Italian nursing bachelor's degree course. Nurse Educ Today. 2012 May;32(4):422-6. doi: 10.1016/j.nedt.2011.03.003.

22. Hoseini BL, Mazloum SR, Jafarnejad F, Foroughipour M. Comparison of midwifery students' satisfaction with direct observation of procedural skills and current methods in evaluation of procedural skills in Mashhad Nursing and Midwifery School. Iran J Nurs Midwifery Res. 2013 Mar;18(2):94-100. PMID: 23983736

23. Wentink, M.M., Siemonsma, P.C., van Bodegom-Vos, L. et al. Teachers' and students' perceptions on barriers and facilitators for eHealth education in the curriculum of functional exercise and physical therapy: a focus groups study. BMC Med Educ.2019;19(343):2-8 doi:10.1186/s12909-019-1778-5

24. Scicluna HA, Grimm MC, Sullivan AJ. et al. Clinical capabilities of graduates of an outcomes-based integrated medical program. BMC Medical Education . 2012; 12(23):2-

8 http://www.biomedcentral.com/1472-6920/12/23

25. Rafiee G, Moattari M, Nikbakht AN, Kojuri J, Mousavinasab M. Problems and challenges of nursing students' clinical evaluation: A qualitative study. Iran J Nurs Midwifery Res. 2014 Jan;19(1):41-9. PMID: 24554959

26. Jamshidi, N.,Molazem, Z., Sharif, F., Torabizadeh, C., Kalyani, M.N., 2016. The challenges of nursing students in the clinical learning environment: A qualitative study. The Scientific World Journal. 2016.doi:10.1155/2016/1846178

\section{Supplementary Files}

This is a list of supplementary files associated with this preprint. Click to download.

- Questionnaire..docx 